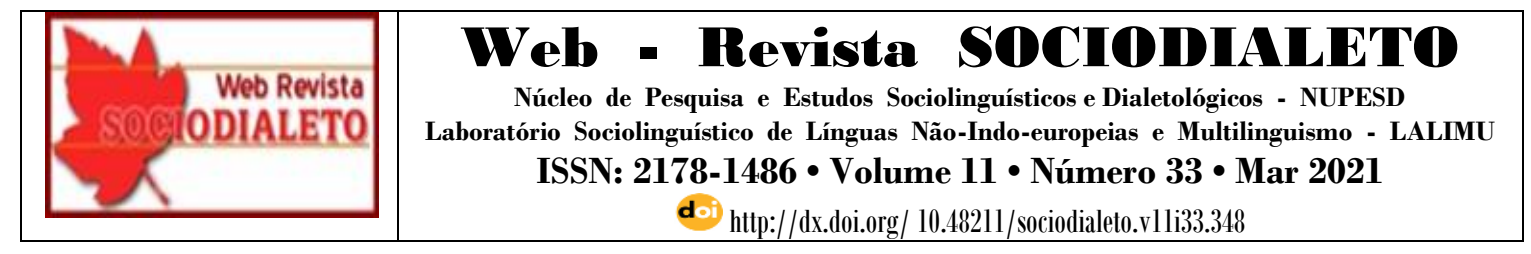

\title{
A FRONTEIRA DO PROCESSO MIGRATÓRIO PARA A MANUTENÇÃO E PERMANÊNCIA DOS ASPECTOS CULTURAIS E LINGUÍSTICOS DE SULISTAS QUE RESIDEM AO NORTE DO ESTADO DE MATO GROSSO ${ }^{1}$
}

\author{
THE BORDER OF THE MIGRATORY PROCESS FOR THE MAINTENANCE AND PERMANENCE OF THE CULTURAL AND \\ LINGUISTIC ASPECTS OF SOUTHERNERS WHO RESIDE IN THE NORTH OF THE STATE OF MATO GROSSO
}

\author{
Priscila Ferreira de Alécio (UNEMAT) ${ }^{2}$ \\ priscilaalecio@hotmail.com
}

\author{
Manoel Mourivaldo Santiago-Almeida (USP) ${ }^{3}$ \\ msantigo@usp.br
}

\begin{abstract}
RESUMO: O processo migratório foi e é muito recorrente na constituição das comunidades do mundo. A luta por melhores condições de vida é tida como uma das causas envoltas no contexto, que propiciam a migração, seja de um país para o outro, seja de uma região para outra. O presente texto tem o objetivo de investigar a fronteira do processo migratório contrapondo ao discurso do colonizador e a realidade do colonizado. Dessa forma, a pesquisa, corrobora com um dos objetivos do trabalho de dissertação, cuja finalidade é obter as atitudes e percepções linguísticas frente a variação "tu" e "você"; em sujeitos que residem no município de Cláudia, no estado de Mato Grosso. A investigação se dará por meio de entrevistas aos migrantes sulistas, constituindo um corpus de 24 sujeitos. O empreendimento está amparado em pressupostos sociolinguísticos, tendo em vista o projeto de investigação relacionado a variação da língua, como também nos autores que tratam dos aspectos fronteiriços. O referencial Sociolinguístico pauta-se em William Labov (2007), Stella Maris Bortoni-Ricardo $(2011$; 2017) dentre outros. A pesquisa encontra-se em fase de elaboração e revisão bibliográfica, mas para este artigo foi realizada quatro entrevistas informante, que chegou na cidade a mais de 20 anos. O resultado, ainda que superficial, aponta para o seguinte: o processo migratório, em sua maioria, constitui-se uma fronteira para a manutenção de aspectos culturais de uma determinada região, comunidade ou sujeito e os aspectos linguísticos, que conforme mostraram os dados, apenas uma migrante faz uso da forma "tu".
\end{abstract}

PALAVRAS-CHAVE: Processo Migratório. Fronteira. Sociolinguística Variacionista. Região Sul.

\begin{abstract}
The migration process has been and is very recurrent in the constitution of the world's communities. The struggle for better living conditions is seen as one of the causes involved in the context, which encourage migration, whether from one country to another or from one region to another. The present text aims at investigating the frontier of the migratory process, opposing the discourse of the colonizer and the reality of the colonized. Thus, the research corroborates one of the objectives of the dissertation, whose purpose is to obtain the linguistic attitudes and perceptions in front of the variation "you" and "you", in

\footnotetext{
${ }^{1}$ Trabalho realizado com o apoio da Coordenação de Aperfeiçoamento Pessoal de Ensino Superior CAPES.

2 Graduação em Letras - Português/Inglês. Mestranda do Programa de Pós-Graduação em Letras (PPGLetras) na Universidade do Estado de Mato Grosso. Também é Bolsista da Coordenação de Aperfeiçoamento Pessoal (CAPES).

${ }^{3}$ Pós-doutor em Filologia de Língua Portuguesa. É professor titular e pesquisador da USP (onde trabalha desde 2004), atualmente, chefe do Departamento de Letras Clássicas e Vernáculas (2017-2021).
} 


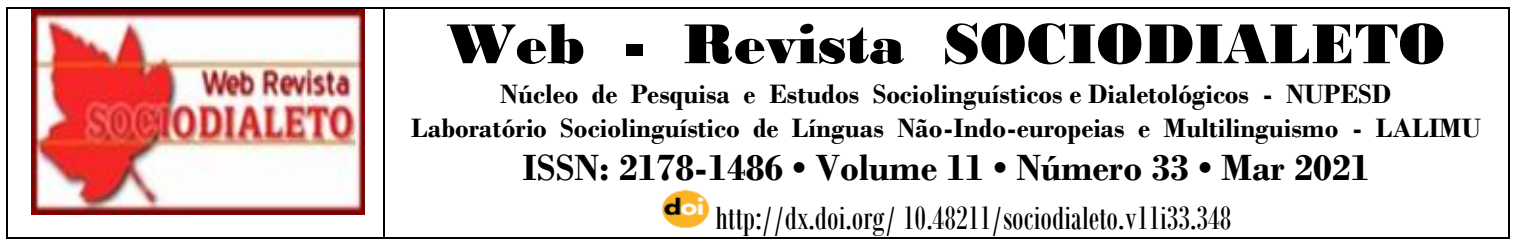

subjects that reside in the municipality of Cláudia, in the state of Mato Grosso. The investigation will be done by means of interviews with Southern migrants, constituting a corpus of 24 subjects. The enterprise is supported by sociolinguistic assumptions, in view of the research project related to the variation of the language, as well as in the authors who deal with the border aspects. The Sociolinguistic framework is based on William Labov (2007), Stella Maris Bortoni-Ricardo $(2011 ; 2017)$ among others. The research is in the elaboration and bibliographical review phase, but for this article four informative interviews were carried out, which arrived in the city more than 20 years ago. The result, although superficial, points to the following: the migration process, in its majority, constitutes a frontier for the maintenance of cultural aspects of a certain region, community or subject, and the linguistic aspects, which as the data showed, only one migrant makes use of the "tu" form.

KEYWORDS: Migratory Process. Border. Sociolinguistics Variationist. Southern Region.

\section{Introdução}

Este trabalho tem o objetivo de expor um dos objetivos de uma pesquisa de mestrado, que versa sobre a análise de atitudes e percepções linguísticas frente a variação "tu" e "você" em migrantes sulistas que residem no município de Cláudia-MT. Busca investigar também, o processo migratório constituinte como uma fronteira para a manutenção da cultura, bem como a fronteira do discurso do colonizador, contrapondo a realidade encontrada pelos migrantes.

O trabalho está organizado em seções que discorrem a respeito do aporte teórico da Sociolinguística Variacionista, área de filiação. A seguir faz-se brevemente a explanação de da Dialetologia e por fim da Dialetologia Perceptual, com as atitudes e percepções linguísticas.

Para obtenção dos resultados, foram analisadas quatro entrevistas com sujeito do sexo feminino, que reside na cidade a mais de 30 anos, bem como morou na região sul, desde pequena. Essa pesquisa é um recorte, dessa forma, optou-se apenas por mulheres, todavia, foram entrevistados homens também, mas aqui dá-se voz ao sexo feminino.

O processo migratório foi tido, pelo discurso colonizador, como algo bom, no entanto, a realidade de muitas migrações, ou até mesmo imigrações, não ocorre dessa forma "a organização social hierarquizada, vertical, que aponta a segregação, separa regiões, determina fronteiras [...]" (TOMÉ, 2009, p. 174). 


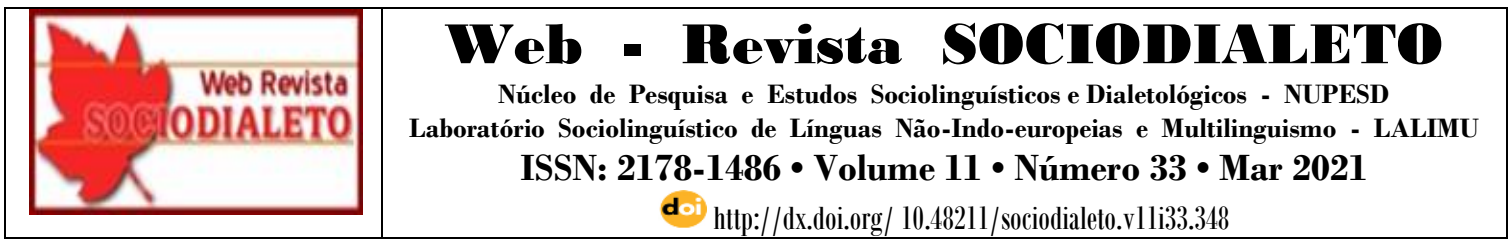

\section{Pressupostos teóricos: Sociolinguística Variacionista}

Alkmim, (2012, p. 35) afirma "que nenhuma língua se apresenta como uma entidade homogênea. Isso significa dizer que qualquer língua é representada por um conjunto de variedades" O contexto social, cultural e os processos migratórios proporcionam a recorrência da heterogeneidade na língua.

Esse estudo surge por intermédio da Sociolinguística que de acordo com Bortoni Ricardo (2017) inicia-se no século XX, como uma disciplina interdisciplinar, cunhada por linguistas muito antes de 1960 "já desenvolviam em seus trabalhos teorias de natureza claramente sociolinguística, como é o caso de Meillet [1866-1936], Bakhtin [1895-1975] e membros do Círculo Linguístico de Praga”. (BORTONI-RICARDO, 2017, p. 11)

A sociolinguística tem por objeto de estudo a língua em uso. A língua por sua vez, pode ser definida, conforme Labov $(2007$, p.2) "o instrumento que as pessoas usam para se comunicar com os outros na vida cotidiana". Ainda nessa perspectiva, Molon e Vianna, (2012, p.147) apoiado na teoria do círculo de Bakhtin, definem a língua como "a realização concreta da interação verbal/discursiva, é a matriz geradora da linguagem, é a realidade fundamental da língua". A sociolinguística tem seus estudos voltados para o social, ou seja, preocupa-se em analisar o contexto e os diversos âmbitos inseridos nesses.

\section{Atitudes e percepções}

Uma área de estudos da Sociolinguística versa sobre as atitudes e percepções linguísticas que, de acordo com Cardoso (2014, p. 14) "um dos fatores de relevância dos estudos sociolinguísticos é depreender como o falante se sente em relação ao dialeto que fala, uma vez que há uma tendência de se categorizar socialmente uma pessoa pelo seu dialeto ou socioleto".

Nessa perspectiva, surge a dialetologia perceptual que tem como ênfase "[...] esclarecer o conhecimento cognitivo dos falantes de línguas variação através da análise 


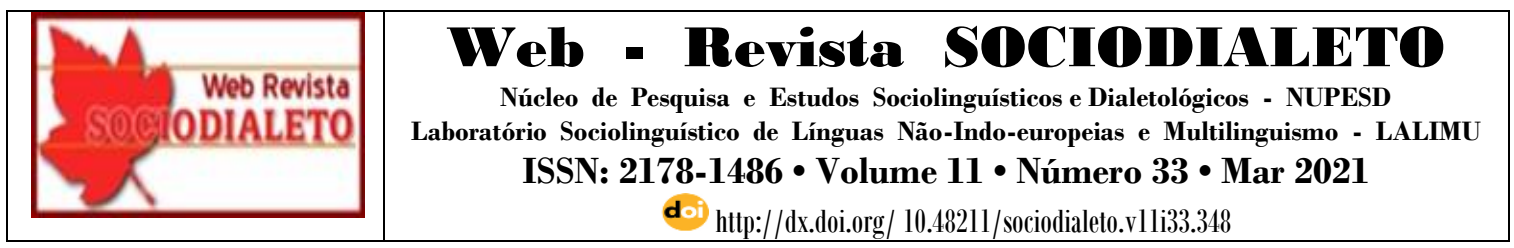

do consciente e do inconsciente reações à percepção da linguagem falada ${ }^{4}$." (HARJUS, 2017, p.3)

A dialetologia perceptual, ou perceptiva, abrangem vários campos (FERREIRA, 2009, p. 254). Ainda de acordo com a autora,

Há percepções geográficas e percepções avaliativas acerca do dinamismo, da correção, da agradabilidade, do valor social, do valor de identidade de uma determinada variedade ou de um traço específico dessa variedade. E o conjunto dessas percepções compõe a percepção de prestígio. (FERREIRA, 2009, p.254)

Oushiro afirma que "os estudos de percepção de cunho variacionista, em geral, deslocaram o interesse sobre diferentes línguas ou variedades linguísticas, como nos estudos supracitados, para o papel de variantes específicas na formação de impressões sociais [...]" (OUSHIRO, 2015, p.269).

De forma ampla, Boughton, (2006) estabelece quarto questões principais, que são utilizadas pela dialetologia perceptual, para analisar o grau de aceitação de determinada variante, em um grupo. "Na sua opinião, a pessoa que fala tem sotaque? É mais provável que a pessoa seja da classe trabalhadora ou da classe média? Você consegue identificar a região de origem da pessoa? Você acha o sotaque da pessoa agradável?” (BOUGHTON, 2006, p. 282). ${ }^{5}$

De acordo com Oushiro, (2015, p. 265) “A habilidade de realizar inferências ao ouvir uma pessoa é tão automática que muitas vezes passa despercebida” Oushiro assevera ainda que "Independentemente de essas inferências estarem corretas ou não, tais impressões provavelmente têm um papel no modo como os membros da comunidade se relacionam e se comunicam entre si." (OUSHIRO, 2015, p. 265).

\footnotetext{
4 "[...] to clarify the cognitive knowledge of speakers about linguistic variation through the analysis of conscious and unconscious reactions to perceived spoken language." (HARJUS, 2017, p.3)

5 "In your opinion, does the person speaking have an accent? Is the person more likely to be working-class or middle-class? Can you identify the person's region of origin? Do you find the person's accent pleasant?" (BOUGHTON, 2006, p. 282)
} 


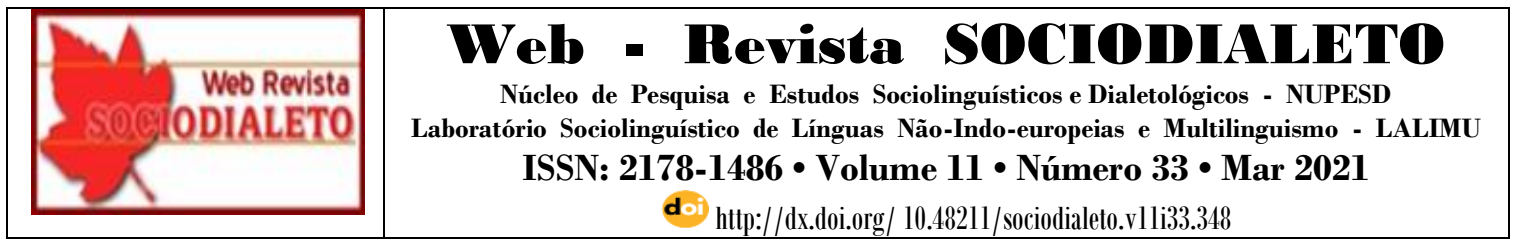

\section{Dialetologia}

A dialetologia, conforme Brandão (1991, p. 79) e uma "a disciplina que se ocupa do estudo de dialetos e falares, isto é, das variedades de natureza geográfica de uma língua". As variações de dialetos são constantemente estudadas pela dialetologia "este tipo de variação linguística tem sido estudado em detalhe pelos dialetologistas." (BRIGHT, 1974 [1960], p. 41).

A disciplina tem por intuito o estudo dos sistemas linguísticos com as variações geográficas e/ou sociais (BORBA, 1976). Dubois assevera que, os estudos dialetológicos tem relação com os dialetos, comuns em uma comunidade de fala.

[...] designa a disciplina que assumiu a tarefa de descrever comparativamente os diferentes sistemas ou dialetos em que uma língua se diversifica no espaço, e de estabelecer-lhe os limites. Emprega-se também para a descrição de falas tomadas isoladamente, sem referência às falas vizinhas ou da mesma família. (DUBOIS, 1978, p. 185)

Conforme Dubois (1978), o dialeto pode ser descrito como uma forma, com sua própria função e mudanças sejam lexicais, fonéticas ou sintáticas que compõem determinada comunidade de fala. Santiago-Almeida argumenta que as pesquisas na área da dialetologia, são como um processo nobre devido ao contato necessário do pesquisador para realizar, conhecer os falantes, de determinado grupo pesquisado, “[...] quem experimenta fazer pesquisa nessa área, [...] percebe logo que, além do interesse científico pelo estudo dos falares regionais e/ou locais, desperta outro muito nobre: é o interesse pelo humano ou pela gente que são agentes desses falares." (SANTIAGO-ALMEIDA, 2013, p. 16)

Dessa forma, a dialetologia surge com o objetivo de estudar os dialetos nos espaços geográficos a fim de constituírem determinada variedade da língua. O campo de estudo são os falares regionais caracterizadas pelas diferenças gramaticais, fonéticas e sintáticas. 


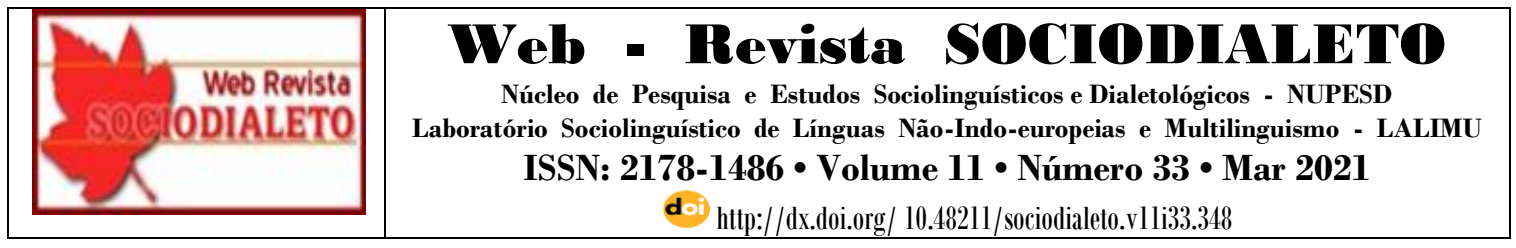

\section{Variação "tu" e "você"}

Durante toda a história das duas formas, há relação com as estruturas sociais (ZENILDA, 2018). Assim, "diferentes estudos sociolinguísticos, nos últimos 30 anos, em diferentes regiões do Brasil, têm evidenciado que a segunda pessoa do singular tem expressão variável com as formas tu e você [...]" (VITORIO, 2018, p. 85). De acordo com Vitorio (2018), as pesquisas evidenciam o quão complexo é o fenômeno, que por sua vez, pode ser condicionado por fatores linguísticos, sociais, geográficos e históricos, portanto, o uso de uma ou outra forma pronominal, por uma determinada comunidade de fala pode ser utilizada para atender os interesses de seus falantes.

A complexidade dos usos tratamentais, como se sabe, não se limita ao valor semântico-social que uma determinada forma de tratamento carrega em si, mas aos valores que os falantes podem atribuir a elas, nas diferentes situações comunicativas que, por si sós, são também complexas. (RUMEU, 2013, p.547).

A forma você surgiu da colocação vossa mercê, utilizada pelo rei em Portugal. No entanto, a expressão vossa mercê, começou a ser utilizada por todos, inclusive aqueles que não pertenciam a Corte, nesse contexto, a forma deixaria de ser empregada, principalmente com relação ao rei, sendo referido como vossa alteza, vossa senhoria e vossa majestade. (MENON, 1995)

Assim, "Vossa Mercê desapareceu do uso honorífico das Cortes em 1490. Já estava sendo empregado por uma parcela considerável da população, provavelmente ainda com valor respeitoso, mas sem a dignidade de forma honorífica" (MENON, 1995, p. 94). Com o desaparecimento da forma "vossa mercê", a forma "você", derivada desse processo, antes era para designar uma relação de superioridade, passa a ser utilizada para uso de igual para igual, desconstruindo a relação de poder que perdurava. (MENON, 1995, p. 95). No Brasil, “[...] diferentemente de Portugal, a forma você(s) passou a ser a forma de tratamento íntimo em quase todo o país, provavelmente em decorrência do uso, desde o início da colonização [...]” (MENON, 1995, p. 95). 


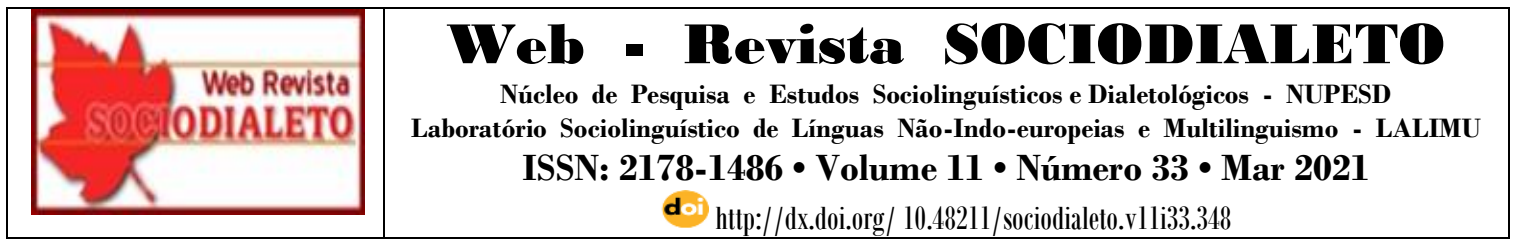

\section{Metodologia de coleta}

Conforme Bauer e Gaskell, a pesquisa qualitativa pode ser utilizada no estágio exploratório da pesquisa, “[...] a pesquisa qualitativa foi considerada apenas no estágio exploratório do processo de pesquisa (pré-desenho), com a finalidade de explorar distinções qualitativas" (BAUER; GASKELL, 2002, p.24), para que haja o conhecimento da pesquisadora com os sujeitos de pesquisa "a fim de se desenvolver mensurações, ou para que se tivesse certa sensibilidade com o campo de pesquisa [...]” (BAUER; GASKELL, 2002, p.24).

De início, tenciona-se aplicar questões, no formato de entrevistas ${ }^{6}$ que, contribuirão para conhecer melhor o processo migratório dos sujeitos. A seguir, aplicarse-á também um questionário com atitudes e percepções linguísticas com relação ao fenômeno variação "tu” e "você". De acordo com Gil (2008, p. 111) a entrevista "é recomendada nos estudos exploratórios, que visam abordar realidades pouco conhecidas pelo pesquisador, ou então oferecer visão aproximativa do problema pesquisado". As entrevistas semiestruturadas são uma forma de "obter uma visão geral do problema pesquisado, bem como a identificação de alguns aspectos da personalidade do entrevistado." (GIL, 2008, p. 111). Assim, o ir a campo é necessário para o bom andamento da pesquisa.

Quadro 1: Representação de sujeitos a serem entrevistados.

\begin{tabular}{|c|c|c|c|}
\hline Grupos & $\mathbf{F}$ & M & Total \\
\hline $\begin{array}{l}\text { Sujeitos migrantes que residem pelo menos } 15 \\
\text { anos - Zona Urbana }\end{array}$ & 4 & 4 & 8 \\
\hline $\begin{array}{l}\text { Sujeitos migrantes que residem pelo menos } 15 \\
\text { anos - Zona Rural }\end{array}$ & 2 & 2 & 4 \\
\hline $\begin{array}{l}\text { Filhos de sulistas migrantes com faixa etária de } \\
18-40 \text { anos - Zona Urbana }\end{array}$ & 4 & 4 & 8 \\
\hline $\begin{array}{l}\text { Filhos de sulistas migrantes com faixa etária de } \\
18-40 \text { anos - Zona Rural }\end{array}$ & 2 & 2 & 4 \\
\hline Total de sujeitos a serem entrevistados & \multicolumn{3}{|c|}{24} \\
\hline
\end{tabular}

\footnotetext{
${ }^{6}$ Esta pesquisa está amparada pelo Comitê de Ética e Pesquisa sob o parecer 4.284.350.
} 


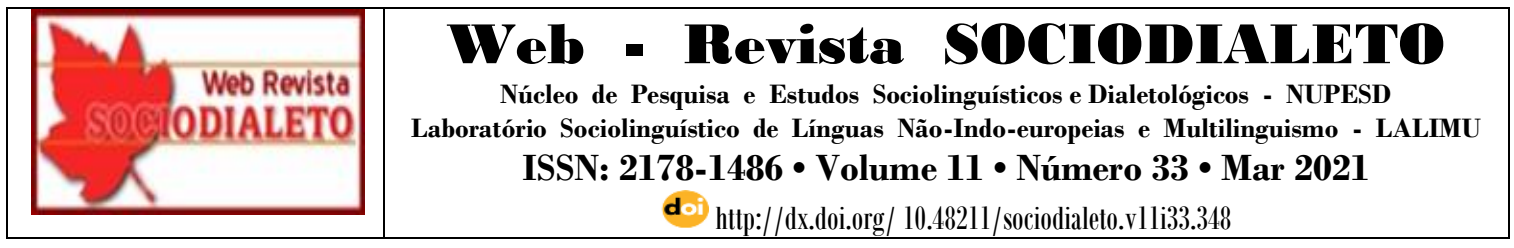

O quadro 1 refere-se a representação dos sujeitos a serem entrevistados no decorrer do trabalho completo. Nesse empreendimento, analisar-se-á apenas as respostas de quatro informantes do sexo feminino apenas, a fim de dar voz as mulheres migrantes.

\title{
6. O município de Cláudia e a fronteira do processo migratório: um olhar para as migrantes
}

O processo de migração ocorre por vários fatores: busca de um lugar melhor, perspectivas diferentes em relação a constituição de morada, oportunidades de emprego, dentre outras. No que concerne ao município de Cláudia, percebe-se, por intermédio de estudos já realizados, que a Colonizadora Sinop teve influência significativa na mudança de sulistas para o município. De acordo com as informações do Portal Cláudia (2020), o município lócus da pesquisa, possui aproximadamente 11.028 habitantes. Ainda conforme o site,

\begin{abstract}
As primeiras famílias que chegaram na década de 70, na sua maioria de origem italiano e grande parte do Rio Grande do Sul e Paraná, acreditaram nas propagandas feitas pela Colonizadora Sinop S.A. e trouxeram consigo sonhos de adquirir mais terras e cultivar café, plantar mandioca para a Sinop Agroquímica S.A, criar gado e trabalhar com a madeira, com muito sacrifício, coragem e fé em Deus, lançaram os alicerces da cidade que nascia em meados de 1978. (PORTAL CLÁUDIA, 2020)
\end{abstract}

A extração madeireira foi, por muitos anos, a principal fonte econômica de recursos para o município com o surgimento atrelado as cidades de Sinop, Vera, Feliz Natal ao qual formavam a Gleba Celeste.

O município foi povoado pela Colonizadora Sinop S.A, por intermédio de folhetos e de divulgação, instigaram as pessoas de outras regiões a investirem no município, constituir morada e, principalmente, investir na produção agropecuária.

[...] as levas de brasileiros do Centro-Sul, que ocorreu para essa área da Região Amazônica, trouxeram consigo, ao lado de sua vocação agrícola, uma série de hábitos de trabalho que, em regra, se chocam com a realidade amazônica, considerando-se seus definidos regimes de chuvas, de graus de solaridade e características de solo. 


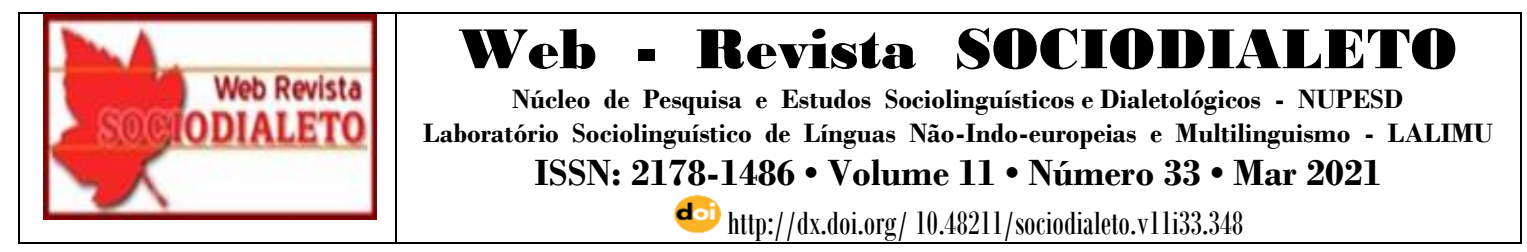

(COLONIZADORA SINOP S.A. Histórico da Gleba Celeste, 5ª Parte, Cidade Cláudia, s.d., fl.01).

Dessa forma, Cláudia tornou-se um município constituído, em sua maioria por migrantes de outras regiões do país, como exemplo, os sulistas, que compõem a maioria no município. Houve também a migração por parte da região sudeste e nordeste, no entanto, a maioria considerável de migrantes constituem os sulistas. Assim, “o objetivo do discurso colonial é apresentar o colonizado como uma população de tipos degenerados com base na origem racial de modo a justificar a conquista e estabelecer sistemas de administração e instrução.” (BHABHA, 2007, p.111).

De acordo com Becker (1997), a urbanização antes mesmo de uma produção agrícola e industrial na fronteira é uma estratégia básica do Estado para a ocupação regional: sustenta a mobilidade permitindo atrair migrantes sem lhes dar acesso à propriedade da terra, e inicia a articulação dos antigos e novos núcleos urbanos entre si e com o mundo exterior. Isso porque os núcleos urbanos desempenham papel fundamental na ocupação, atraindo fluxos migratórios, organizando o mercado de trabalho e o controle social. (TEIXEIRA, 2006, p. 28)

Cláudia possui atualmente, uma economia que gira da agricultura e pecuária, as duas fontes que desde o início da constituição do município, esteve presente na base econômica.

A pesquisa encontra-se em fase de revisão bibliográfica, mas para este trabalho fez-se necessário ir a campo para entrevistar um sujeito migrante, do sexo feminino que reside a 35 anos no município de Cláudia. Para manter o sigilo do nome do sujeito, será utilizada a sigla SF, que designa, sujeito do sexo feminino. Quando questionado sobre o Bairro quando chegou em Cláudia, o sujeito descreveu da seguinte forma,

SF1: Olha, tinha três ou quatro casa num quarterão, poucos moradores, poucos, e a cidade era bem pequena ainda, muito pequena.

P: A senhora poderia descrever quais características o bairro possuía quando a senhora chegou no bairro?

SF1:Praça não tinha nada, do lado de baixo, onde é a feira dos produtores, era só mata, tinha macaco, tinha bicho preguiça, tinha porco 


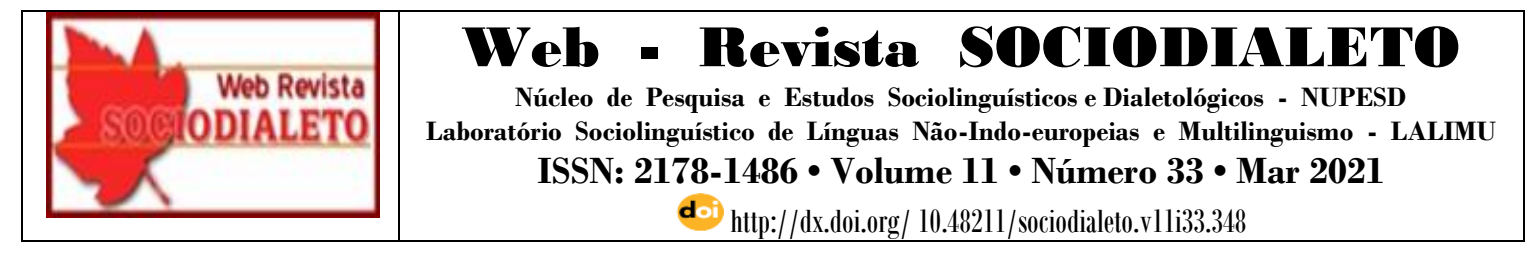

espinho... era a nossa a casa do senhor X, do Y, umas quatro casa, não tinha outros moradores.

A informante cita nomes na hora da entrevista, assim, foi utilizada as letras X e Y a fim de preservar a identidade. Conforme Tomé (2009, p. 34) "e este homem e esta mulher tiveram de aprender a movimentar por esses labirintos.” Ao ser questionada o porquê da escolha de morar no bairro, respondeu da seguinte forma

SF1: Na verdade não foi escolha, como a cidade estava iniciando, a gente comprou o terreno, ficou local de trabalho e moradia

Dessa forma, “apesar do ‘jogo’ no sistema colonial que é crucial para seu exercício de poder, o discurso colonial produz ao colonizado como uma realidade social, que é ao mesmo tempo do "outro" e ainda assim inteiramente apreensível e visível." (BHABHA, 2007, p.111). O sujeito demonstrou que a cidade não havia condições de moradia, tendo em vista que teria de ser explorado, necessitando que os próprios moradores construíssem a morada, bem como pudesse ter opções de lazer.

\section{A variação "tu" e "você"}

A fim de observar o tempo de residência das informantes, fez-se necessário a elaboração de um quadro com o perfil. O tempo de residência no município de Cláudia, bem como a idade, são os fatores que são considerados para este trabalho.

Quadro 2: Perfil das informantes.

\begin{tabular}{|c|c|c|c|}
\hline Sigla & Idade & $\begin{array}{ll}\text { Tempo } & \text { de } \\
\text { residência } & \text { em } \\
\text { Cláudia } & \end{array}$ & $\begin{array}{l}\text { Variação } \\
\text { predominante }\end{array}$ \\
\hline SF1 & 45 anos & 25 anos & Tu/você \\
\hline SF2 & 57 anos & 35 anos & Você \\
\hline SF3 & 49 anos & 38 anos & $\mathrm{Tu}$ \\
\hline SF4 & 60 anos & 20 anos & você \\
\hline
\end{tabular}

Fonte: Elaborado pelos autores, 2020. 


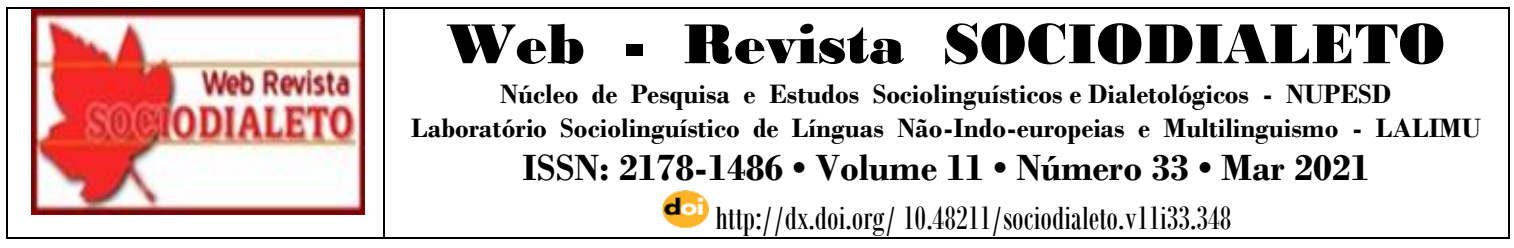

A SF1 tem 45 anos de idade, com tempo de residência em 25 anos e a variação predominante em "tu" e "você" ou seja faz uso das duas formas. A SF2 possui 57 anos de idade, com 35 anos de residência em Cláudia e com a forma predominante "você", SF3, com 49 anos de idade, tempo de residência em 38 anos e forma predominante "tu". Por fim, SF4, 60 anos de idade, 20 anos de residência na cidade e forma predominante "você". As perguntas do teste de atitudes foram baseadas nas questões de Oushiro (2015), voltado para a variação "tu" e "você". No quadro a seguir é exposto as perguntas do questionário de atitudes e percepções linguísticas.

\section{Quadro 3: Questionário de Atitudes e Percepção Linguísticas.}

\section{Questionário de Atitudes e Percepção Linguísticas}

Vamos imaginar situações de diálogo entre pessoas do seu convívio: seus familiares, seus amigos, os moradores do município de um modo geral.

1. Um vizinho de seu bairro se encontra com outro na rua e quer saber se ele vai ao supermercado naquele dia. Como ele faz a pergunta?

2. Um vizinho encontra seu sobrinho na rua e quer saber se ele já foi ao supermercado. Como seria a pergunta?

3. Dois amigos seus combinaram de ir ao clube da cidade no final de semana. Porém, aconteceu um imprevisto e um deles não pôde ir. Como o amigo que foi perguntaria ao outro por que ele não compareceu?

4. Dois colegas de trabalho estão conversando e um quer saber do outro se ele foi a uma festa acontecida na comunidade no dia anterior. De que maneira ele perguntaria?

5. E se essa mesma pergunta fosse feita à sua sobrinha, como seria?

6. E se perguntasse ao seu pai?

7. E se essa mesma pergunta sobre a ida à festa seu colega fizesse à/ao irmã/irmão dele ou primo (a), como seria?

8. Percebeu alguma diferença entre as perguntas feitas quanto à forma de as pessoas se tratarem?

9. Se sim, qual a diferença?

10. Você sabe por que isso acontece?

11. Se estiver na escola e precisar pedir à supervisora para avisar a sua mãe que não está passando bem, como faria o pedido a ela?

12. Nas conversas com seu pai, como o trata: 'tu', 'você', ou 'o senhor'? 


\begin{tabular}{|c|c|}
\hline $\begin{array}{l}\text { Web Revista } \\
\text { ODIALETO }\end{array}$ & 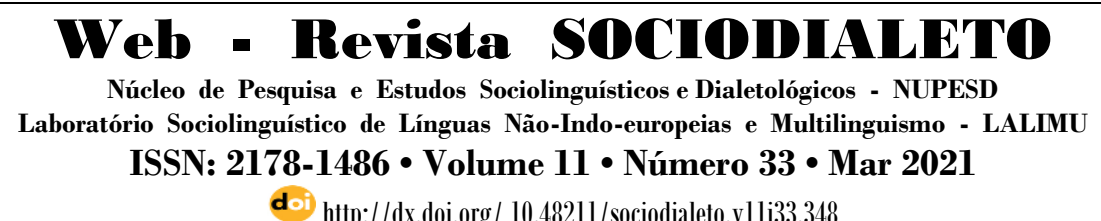 \\
\hline
\end{tabular}

\section{Por quê?}

14. E quando conversa com seu(s) irmão(s), como o(s) trata, usando o 'tu' ou o 'você'? 15. Qual sua forma preferida para tratar uma pessoa quando está conversando com ela, usando o 'tu' ou 'você'?

16. E qual a forma que mais usa: 'tu' ou 'você'?

17. Sabe por que isso acontece?

Fonte: Adaptado de Oushiro, 2015.

O teste de atitudes assim como as entrevistas ainda estão em desenvolvimento, mas a partir da análise dos dados obtidos das 4 entrevistadas migrantes, observou-se que, quando questionada no teste do uso da variação as repostas foram as seguintes:

Quadro 3: Respostas ao teste da variação "tu" e "você".

\begin{tabular}{|c|c|c|c|c|}
\hline & SF1 & SF2 & SF3 & SF4 \\
\hline $\begin{array}{l}\text { Um vizinho de seu bairro } \\
\text { se encontra com outro na } \\
\text { rua e quer saber se ele vai } \\
\text { ao supermercado } \\
\text { naquele dia. Como ele faz } \\
\text { a pergunta? }\end{array}$ & $\begin{array}{l}\text { Você vai ao } \\
\text { mercado? }\end{array}$ & $\begin{array}{l}\text { Você vai ao } \\
\text { mercado } \\
\text { hoje? }\end{array}$ & $\begin{array}{l}\text { Tu vai no } \\
\text { mercado } \\
\text { hoje? }\end{array}$ & $\begin{array}{l}\text { Tu vai trazer o } \\
\text { que do } \\
\text { mercado } \\
\text { hoje? }\end{array}$ \\
\hline $\begin{array}{l}\text { Um vizinho encontra seu } \\
\text { sobrinho na rua e quer } \\
\text { saber se ele já foi ao } \\
\text { supermercado. Como } \\
\text { seria a pergunta? }\end{array}$ & $\begin{array}{l}\text { Você foi no } \\
\text { mercado? }\end{array}$ & $\begin{array}{l}\text { Você já foi o } \\
\text { supermercado } \\
\text { hoje? }\end{array}$ & $\begin{array}{l}\text { Tu já foi no } \\
\text { mercado } \\
\text { hoje guri? }\end{array}$ & $\begin{array}{l}\text { Você já foi ao } \\
\text { mercado? }\end{array}$ \\
\hline $\begin{array}{l}\text { Dois amigos seus } \\
\text { combinaram de ir ao } \\
\text { clube da cidade no final } \\
\text { de semana. Porém, } \\
\text { aconteceu um imprevisto } \\
\text { e um deles não pôde ir. } \\
\text { Como o amigo que foi } \\
\text { perguntaria ao outro por } \\
\text { que ele não compareceu? }\end{array}$ & $\begin{array}{l}\text { Por que tu } \\
\text { não foi no } \\
\text { clube? }\end{array}$ & $\begin{array}{l}\text { Por que você } \\
\text { não foi a } \\
\text { festa? }\end{array}$ & $\begin{array}{l}\text { Guri, mas } \\
\text { porque que } \\
\text { tu não foi } \\
\text { no clube? }\end{array}$ & $\begin{array}{l}\text { Por que você } \\
\text { me deixou na } \\
\text { mão/ Por que } \\
\text { você não foi } \\
\text { no encontro? }\end{array}$ \\
\hline $\begin{array}{l}\text { Dois colegas de trabalho } \\
\text { estão conversando e um } \\
\text { quer saber do outro se ele } \\
\text { foi a uma festa acontecida } \\
\text { na comunidade no dia } \\
\text { anterior. De que maneira } \\
\text { ele perguntaria? }\end{array}$ & $\begin{array}{l}\text { Você gostou } \\
\text { da festa? }\end{array}$ & $\begin{array}{l}\text { Você chegou } \\
\text { a ir à festa } \\
\text { ontem à } \\
\text { noite? }\end{array}$ & $\begin{array}{l}\text { Tu foi na } \\
\text { festa que } \\
\text { teve } \\
\text { ontem? }\end{array}$ & $\begin{array}{l}\text { Para que lado } \\
\text { você foi? }\end{array}$ \\
\hline
\end{tabular}

Fonte: Elaborado pelos autores, 2020. 


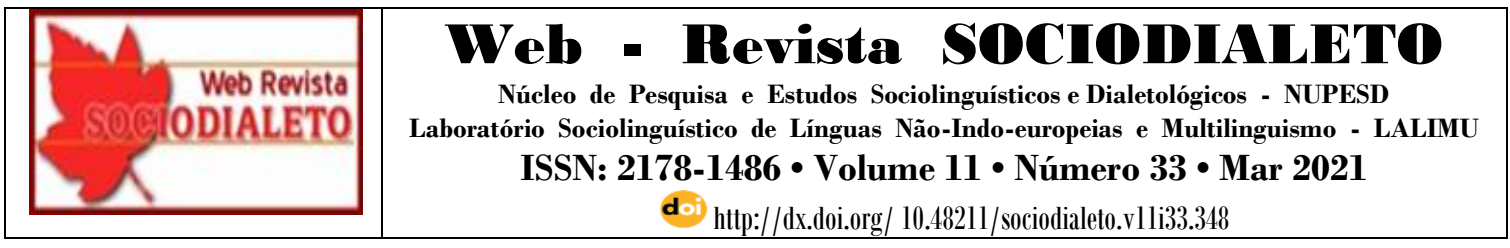

Percebe-se que a variação "tu” já não é mais recorrente em todas as entrevistadas, tendo em vista que apenas uma demonstrou utilizar a variação. A SF3 reside a 38 anos na cidade, mas ainda preservar a variação "tu” característico da região sul do país, no entanto demonstrou o uso do "tu" sem a concordância, ou seja, proferiu "tu vai" que na gramática está como "tu vais". Dessa forma as outras entrevistadas possuem outras características, como tomar chimarrão. No que concerne ao aspecto linguístico, percebe-se que utilizam a vibrante 'r', também característico da região sul.

No que concerne as perguntas expostas nesse trabalho, pôde-se perceber a variação você, tendo em vista o tempo de residência na cidade. Desta feita, as entrevistadas demonstraram, em sua maioria que o processo migratório interferiu no processo de manutenção da variação recorrente do sul.

\section{Considerações finais}

A Sociolinguística é a área que estuda a língua no contexto social, bem como os fatores que regem a sociedade. Dessa forma, o que está atrelado a constituição do sujeito, seja na linguagem, ou nos fatores que regem a sociedade. Assim, o objetivo desse trabalho foi expor como será desenvolvida a pesquisa com a variação "tu" e "você", como também os aspectos fronteiriços que constituem/constituíram o processo de migração para o município de Cláudia.

A entrevista foi para ilustrar como o discurso do colonizador, não convém com o da migração, tendo em vista que a informante relatou como era o bairro quando chegou da região sul. Assim, percebe-se, que o grande desafio foi adentrar uma cidade que não havia estrutura para morada, conforme relatos da entrevistada.

A pesquisa encontra-se em fase de revisão bibliográfica e aplicação de entrevistas, mas a partir desses pressupostos pode-se inferir que o processo migratório para o município de Cláudia foi de intensa descoberta, seja na moradia, ou até mesmo nos desafios que compõem o processo. 


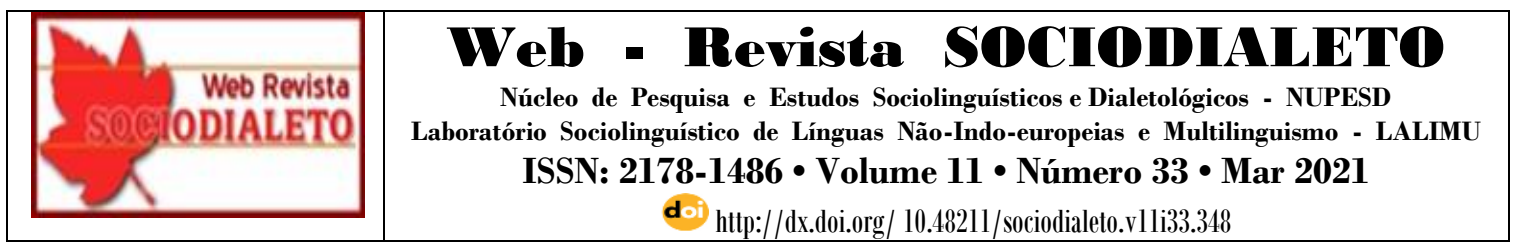

O processo migratório promoveu a variação "você" como recorrente em três das quatro entrevistadas. Apenas uma utilizou o "tu" bem como outros aspectos que são característicos do falar sulista. No entanto, houve a percepção de que o 'r' vibrante ainda se faz presente, em todas, mas como não é o foco desse trabalho, poderá despertar futuras pesquisas.

\section{REFERÊNCIAS}

ALKMIM, Tania Maria. Sociolinguística: Parte 1. In: MUSSALIM, Fernanda; BENTES, Ana Christina (Orgs). Introdução a Linguística: Domínios e fronteiras - Volume 1, $9^{\text {a }}$ edição, São Paulo: Cortez, 2012.

BORTONI-RICARDO, Stella Maris. Manual de Sociolinguística. 1. ed., 1. Reimpressão, São Paulo: Contexto, 2017.

BAUER, Martin W; GASKELL, George. Qualitative Researching with Text, Image and Sound: a Pratical Handbook. Pesquisa qualitativa com texto: imagem e som: um manual prático. Tradução de GUARESCHI, Pedrinho A. - Petrópolis, RJ: Vozes, 2002.

BHABHA, Homi K. O local da cultura. Belo Horizonte: Editora UFMG. 2007.

BORBA, Francisco da Silva. Pequeno vocabulário de lingUística moderna. $2^{\mathrm{a}} \mathrm{ed}$. rev. e aum. São Paulo : Nacional, 1976.

BOUGHTON, ZO 'E. When perception isn't reality: Accent identification and perceptual dialectology in French. French Language Studies 16 (2006), 277-304, C Cambridge University Press doi:10.1017/S0959269506002535.

CARDOSO, Denise Porto. Atitudes linguísticas e avaliações subjetivas de alguns dialetos brasileiros. São Paulo; Blucher, 2015.

BRANDÃO, Silvia Figueiredo. A geografia linguística no Brasil. São Paulo: Ática, 1991.

BRIGHT, William. Dialeto social e história da linguagem. In FONSECA, Maria Stella Vieira da; NEVES, Moema Facure (Orgs.). Sociolinguística. Rio de Janeiro: Eldorado, 1974.

COLONIZADORA SINOP S.A. Histórico da Gleba Celeste - 5a . Parte: Cidade Cláudia. Sinop, s.d. 5fls.

DUBOIS, Jean et alii. Dicionário de lingüística. São Paulo : Cultrix, 1978.

FERREIRA, Carla Sofia Silva. Percepções dialectais e atitudes linguísticas. O método da Dialectologia perceptual e as suas potencialidades. Textos Selecionados. XXIV Encontro Nacional da Associação Portuguesa de Linguística, Lisboa, APL, 2009, pp. 251263. 


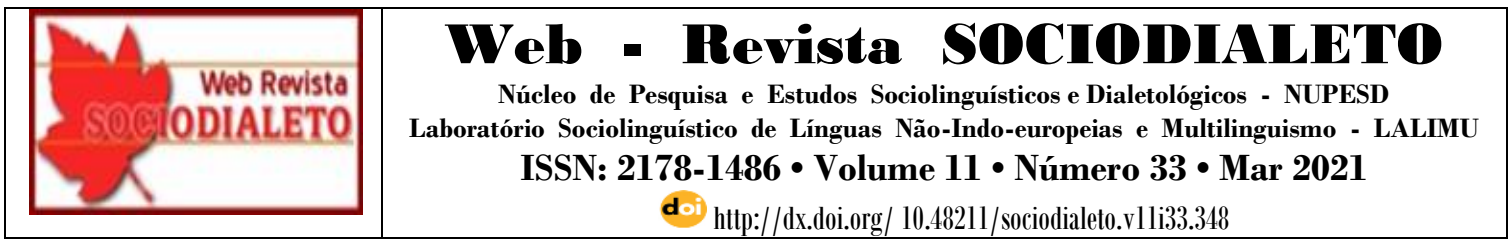

GIL, Antonio Carlos. Como elaborar projetos de pesquisa. - 4. ed.; São Paulo : Atlas, 2002.

GIL, Antonio Carlos. Métodos e técnicas de pesquisa social. 6 edição; São Paulo, Atlas; 2008.

LABOV, William. Sociolinguística: uma entrevista com William Labov. Revista Virtual de Estudos da Linguagem - ReVEL. Vol. 5, n. 9, agosto de 2007. Tradução de Gabriel de Ávila Othero. ISSN 1678-8931 [www.revel.inf.br].

MOLLON, Newton Duarte; VIANNA, Rodolfo. O Círculo de Bakhtin e a Linguística Aplicada / The Bakhtin Circle and Applied Linguistics. Bakhtiniana, São Paulo, 7 (2): 142-165, Jul./Dec. 2012.

OUSHIRO, Lívia. Identidade na pluralidade: Avaliação, produção e percepção linguística na cidade de São Paulo. Tese. Orientador: Prof. Dr. Ronald Beline Mendes. Universidade de São Paulo. 2015.

REIS, Zenilda Mendes. A variação de 'tu' e 'você' no português falado e escrito em Lontra - MG. Dissertação - Universidade Estadual de Montes Claros - Unimontes, Programa de Pós-Graduação em Letras - Linguagens e Letramentos/PPGL, 2018. Dissertação. Orientadora: Prof. ${ }^{a}$ Maria do Socorro Vieira Coelho.

RUMEU, Márcia Cristina de Brito. A variação tu e você no português brasileiro oitocentista e novecentista: reflexões sobre a categoria social gênero. Alfa, São Paulo, 2013. p. 545-576.

SANTIAGO-ALMEIDA, Manoel Mourivaldo. Desde antes do português brasileiro. Revista de Letras Norteamentos Estudos Linguísticos, Sinop, v. 6, n. 12, p. 16-30, jul./dez. 2013.

TEIXEIRA, Luciana. A Colonização no Norte de Mato Grosso: O Exemplo da Gleba Celeste. 2006. 118f. Dissertação (Mestrado em Geografia) - Faculdade de Ciências e Tecnologia da Universidade Estadual Paulista - UNESP, Presidente Prudente, 2006.

TOMÉ, Cristinne Leus. O Início da escolarização municipal em Cláudia. Revista Eventos Pedagógicos v. 1, n.1 (1. ed. rev. e aum.), p. 95-103, ago./dez. 2010.

TOMÉ, Cristinne Leus. "Eu não sou professor, não": a presença do professor na cidade Cláudia entre 1978 e 1988.317f. 2009, Tese (Doutorado em Educação) - Universidade Federal do Rio Grande do Sul, Porto Alegre, 2009.

VITÓRIO, Elyne Giselle de Santana Lima Aguiar. A variação tu e você em Maceió, Alagoas. Todas As Letras, São Paulo, v. 20, n. 2, p. 85-99, maio/ago. 2018 http://dx.doi.org/10.5935/1980-6914/letras.v20n2p85-99.

Recebido em: 30/10/2020 | Aprovado em: 15/01/2021. 